\title{
Clues for a standardised thermal-optical protocol for the assessment of organic and elemental carbon within ambient air particulate matter
}

\author{
L. Chiappini ${ }^{1}$, S. Verlhac ${ }^{1}$, R. Aujay ${ }^{1}$, W. Maenhaut ${ }^{2}$, J. P. Putaud ${ }^{3}$, J. Sciare ${ }^{4}$, J. L. Jaffrezo ${ }^{5}$, C. Liousse $^{6}$, \\ C. Galy-Lacaux ${ }^{6}$, L. Y. Alleman ${ }^{7}$, P. Panteliadis ${ }^{8}$, E. Leoz ${ }^{1}$, and O. Favez ${ }^{1}$ \\ ${ }^{1}$ Institut National de l'Environnement Industriel et des Risques, Parc Technologique ALATA, \\ 60550 Verneuil-en-Halatte, France \\ ${ }^{2}$ Ghent University (UGent), Department of Analytical Chemistry, Krijgslaan 281, S12, 9000 Gent, Belgium \\ ${ }^{3}$ European Commission, Joint Research Centre, TP 050, 21027 ISPRA, Italy \\ ${ }^{4}$ Laboratoire des Sciences du Climat et l'Environnement (LSCE, CEA-CNRS-UVSQ), CEA-Orme des Merisiers, \\ 91191 Gif-sur-Yvette, France \\ ${ }^{5}$ Université Grenoble Alpes, CNRS, LGGE, 38000 Grenoble, France \\ ${ }^{6}$ Laboratoire d'aérologie, UMR5560, Université Paul Sabatier, 14 avenue Edouard Belin, 31400 Toulouse, France \\ ${ }^{7}$ Mines Douai, SAGE, CS10838, 59508 Douai, France \\ ${ }^{8}$ GGD, Department of Air Quality, Public Health Service Amsterdam, 1018WT, the Netherlands
}

Correspondence to: O. Favez (olivier.favez@ineris.fr)

Received: 2 August 2013 - Published in Atmos. Meas. Tech. Discuss.: 29 November 2013

Revised: 26 April 2014 - Accepted: 30 April 2014 - Published: 10 June 2014

\begin{abstract}
Along with some research networking programmes, the European Directive 2008/50/CE requires chemical speciation of fine aerosol $\left(\mathrm{PM}_{2.5}\right)$, including elemental (EC) and organic carbon (OC), at a few rural sites in European countries. Meanwhile, the thermal-optical technique is considered by the European and US networking agencies and normalisation bodies as a reference method to quantify EC-OC collected on filters. Although commonly used for many years, this technique still suffers from a lack of information on the comparability of the different analytical protocols (temperature protocols, type of optical correction) currently applied in the laboratories. To better evaluate the EC-OC data set quality and related uncertainties, the French National Reference Laboratory for Ambient Air Quality Monitoring (LCSQA) organised an EC-OC comparison exercise for French laboratories using different thermaloptical methods (five laboratories only). While there is good agreement on total carbon (TC) measurements among all participants, some differences can be observed on the EC/TC ratio, even among laboratories using the same thermal protocol. These results led to further tests on the influence of the optical correction: results obtained from different European
\end{abstract}

laboratories confirmed that there were higher differences between $\mathrm{OC}_{\mathrm{TOT}}$ and $\mathrm{OC}_{\mathrm{TOR}}$ measured with NIOSH 5040 in comparison to EUSAAR-2. Also, striking differences between $\mathrm{EC}_{\mathrm{TOT}} / \mathrm{EC}_{\mathrm{TOR}}$ ratios can be observed when comparing results obtained for rural and urban samples, with $\mathrm{EC}_{\mathrm{TOT}}$ being $50 \%$ lower than $\mathrm{EC}_{\mathrm{TOR}}$ at rural sites whereas it is only $20 \%$ lower at urban sites. The PM chemical composition could explain these differences but the way it influences the EC-OC measurement is not clear and needs further investigation. Meanwhile, some additional tests seem to indicate an influence of oven soiling on the EC-OC measurement data quality. This highlights the necessity to follow the laser signal decrease with time and its impact on measurements. Nevertheless, this should be confirmed by further experiments, involving more samples and various instruments, to enable statistical processing. All these results provide insights to determine the quality of EC-OC analytical methods and may contribute to the work toward establishing method standardisation. 


\section{Introduction}

The European Directive 2008/50/EC on ambient air quality and cleaner air for Europe requires measurements of elemental carbon (EC) and organic carbon (OC) in fine aerosols $\left(\mathrm{PM}_{2.5}\right.$, i.e. particles having aerodynamic diameter below $2.5 \mu \mathrm{m})$ at rural background sites. This is in line with several recommendations arising from the scientific community stressing the need to monitor these components in Europe (e.g. Kahnert et al., 2004). However, there is still no universal standard procedure to quantify these carbonaceous fractions in PM and important discrepancies have been observed worldwide between different instruments and analytical protocols. These differences can bring large uncertainties when comparing data sets, estimating combustion sources or modelling the impact of carbonaceous aerosol on climate (Vignati et al., 2010).

In this context, the European Committee for Standardisation is currently working on a common standardised methodology (CEN/TC 264 TR 16243). As recommended by the scientific community and implemented in the United States, this methodology will be based on thermal-optical techniques. Based on the differentiation between EC and OC according to their thermal and optical properties, such methods primarily consist of two progressive heating steps and one internal calibration. The desorption of carbonaceous matter from the filter sample begins under an inert gas (He) and continues in a second step under an oxidising atmosphere $\left(\mathrm{He} / \mathrm{O}_{2}\right)$. The carbon volatilised from the filter is catalytically oxidised into $\mathrm{CO}_{2}$ which can be measured directly with a non-dispersive infrared detector (Chow et al., 1993) or indirectly by a flame ionisation detector (FID) after quantitative reduction to $\mathrm{CH}_{4}$ (Birch and Cary, 1996). Ideally, the whole OC content should be desorbed during the first step while EC should be burned off under the oxidising atmosphere at the higher temperature. This is, however, not the case as a fraction of the OC is pyrolytically converted to EC (Huntzicker et al., 1982). This OC fraction, usually referred to as pyrolysed organic carbon (POC), evolves off the filter under the oxidative atmosphere, concomitantly to the genuine EC, resulting in a bias when discriminating EC and OC. To overcome this artefact, a continuous monitoring of the filter transmittance (TOT) and/or reflectance (TOR) is highly recommended (Dod et al., 1978; Johnson and Huntzicker, 1979).

Three different thermal protocols are nowadays commonly used: the IMPROVE (Interagency Monitoring of Protected Visual Environments) and NIOSH 5040 (U.S. National Institute for Occupational Safety and Health) protocols have been implemented within networking activities in the US and worldwide since the 1990s, while the EUSAAR-2 protocol has been optimised more recently in the framework of the European project EUSAAR (European Supersites for Atmospheric Aerosol Research, Cavalli et al., 2010). These protocols (Table 1), developed mainly for background sites (IMPROVE and EUSAAR-2) and urban sites (NIOSH), differ in their highest temperature set points in an inert atmosphere, higher for NIOSH 5040 (up to $850^{\circ} \mathrm{C}$ under the He atmosphere step) than for IMPROVE and EUSAAR-2 (up to about 580 and $650^{\circ} \mathrm{C}$, respectively), in the durations of the temperature step (longer for IMPROVE and EUSAAR-2) and in the optical correction type: reflectance for IMPROVE, transmittance for NIOSH and EUSAAR-2. Differences up to a factor of two have been observed by Chow et al. (2001) when comparing the IMPROVE and NIOSH protocols. Chow et al. (2004) demonstrated that EC measured with TOT correction is $30 \%$ lower than EC measured with TOR correction when employing the same thermal protocol, whereas it is 70 to $80 \%$ lower when comparing a low-temperature protocol (IMPROVE) and a high-temperature protocol (NIOSH). Schauer et al. (2003) also evidenced that the EC-OC split is highly sensitive to the temperature programme used.

Moreover, the optical correction for charring is not the only source of discrepancies: the temperature and residence time at each thermogram plateau, as well as the catalysts used, are among the many parameters that can influence ECOC measurements (Schmid et al., 2001; Schauer et al., 2003; Chow et al., 2004).

As strongly recommended by the European Commission and to better understand the quality of EC-OC data provided by thermal-optical analyses, the French Reference Laboratory for Ambient Air Quality Monitoring (LCSQA) organised an EC-OC comparison exercise in 2010 for the five laboratories using thermal-optical methods for EC-OC measurement in France at that time. To investigate the discrepancies observed between these laboratories, further comparisons were performed on results obtained from the analysis of samples from different European sites with the optical reflectance (TOR) and transmittance (TOT) charring corrections. The influences of the EC filter loading and the laser signal on the EC-OC split were also addressed.

\section{Interlaboratory exercise organisation}

\subsection{Methodology}

\subsubsection{Participating laboratories and instruments used}

All five French laboratories performing routine off-line ECOC thermal-optical analyses, participated in the intercomparison exercise which was conducted in spring 2010 on $\mathrm{PM}_{10}$ ambient air filters that were collected in October 2009. A code number was assigned to each laboratory to preserve anonymity. Since the aim of this exercise was to evaluate the uncertainties related to $\mathrm{EC}-\mathrm{OC}$ measurements in the present state of the art (i.e. no unique standard protocol is available), each laboratory was asked to analyse the samples (test materials) with its routine procedure. Table 1 lists the different methodologies and instruments used by the participants. Three different thermal protocols were 
Table 1. Analytical protocols, type of charring correction and instrument used by each laboratory in the French intercomparison.

\begin{tabular}{llll}
\hline & NIOSH 5040 & IMPROVE & EUSAAR_2 \\
\hline Laboratory code & 2 & 3 & $1,4,5$ \\
\hline Step & & $T\left({ }^{\circ} \mathrm{C}\right)$, duration (s) \\
\hline $\mathrm{He} 1$ & 250,60 & $120,150-580$ & 200,120 \\
$\mathrm{He} 2$ & 500,60 & $250,150-580$ & 300,150 \\
$\mathrm{He} 3$ & 650,60 & $450,150-580$ & 450,180 \\
$\mathrm{He} 4$ & 850,90 & $550,150-580$ & 650,180 \\
$\mathrm{He} / \mathrm{O}_{2} 1$ & 650,30 & $550,150-580$ & 500,120 \\
$\mathrm{He} / \mathrm{O}_{2} 2$ & 750,30 & $700,150-580$ & 550,120 \\
$\mathrm{He} / \mathrm{O}_{2} 3$ & 850,30 & $800,150-880$ & 700,70 \\
$\mathrm{He} / \mathrm{O}_{2} 4$ & 940,120 & & 850,80 \\
\hline Charring correction & Transmittance & Reflectance and & Transmittance \\
& & Transmittance & \\
\hline Laboratory and & Lab. 2, Sunset Lab. Inst. & Lab. 3, DRI Model & Lab. 1 Sunset Lab. Inst \\
instrument type & & & Lab. 4 Sunset Lab. Inst. \\
& & & Lab. 5 Sunset Lab.Inst. \\
\hline
\end{tabular}

employed: EUSAAR-2, NIOSH 5040 and IMPROVE. For the sake of clarity, a colour was assigned to each protocol: red for EUSAAR-2, yellow for NIOSH 5040 and green for IMPROVE.

\subsubsection{Test materials}

Real ambient air $\mathrm{PM}_{10}$ samples collected on pre-baked (at $500^{\circ} \mathrm{C}$ during $2 \mathrm{~h}$ ) Whatman QM-A quartz fiber filters of $150 \mathrm{~mm}$ diameter were chosen as test material. The samples were collected with high-volume samplers (DA80, Digitel) during $24 \mathrm{~h}$ with an operating flow rate of $30 \mathrm{~m}^{3} \mathrm{~h}^{-1}$ at two urban sites within the CARA programme (PM chemical characterisation (Chiappini et al., 2010; Colette et al., 2010)). Three filter samples displaying different $\mathrm{PM}_{10}$ concentration levels denoted N1, N2 and N3 and corresponding to 19, 68 and $32 \mu \mathrm{g} \mathrm{cm}^{-2}$ of total carbon (TC) respectively (10, 45 and $70 \mu \mathrm{g} \mathrm{m}^{-3}$ ), as measured by INERIS with the EUSAAR-2 method, were chosen from the sets available. Each laboratory received three $1.5 \mathrm{~cm}^{2}$ punches of each filter and three punches from a blank filter also pre-baked (i.e. total of 12 punches per laboratory).

Prior to the comparison exercise, the homogeneity of the sample deposits collected with the DA80 sampler was checked at INERIS by comparing TC, EC and OC concentrations on central and surrounding punches. A total number of 18 punches were taken from each of three sampled filters, denoted $\mathrm{N}^{\prime} 1, \mathrm{~N}^{\prime} 2, \mathrm{~N}^{\prime} 3$, chosen so that they were similar to the test samples N1, N2 and N3 (same sampler, same sampling site, same period, similar $\mathrm{PM}_{10}$ concentration levels). The overall relative standard deviation (RSD) was below $5 \%$ for TC and ranged between 2 and $6 \%$ for OC and between 3 and $4 \%$ for EC. The higher RSD obtained for $\mathrm{N}^{\prime} 1$ could be
Table 2. Mean, standard deviation (SD), relative standard deviation (RSD) obtained for the 18 punches made on filters $\mathrm{N}^{\prime} 1, \mathrm{~N}^{\prime} 2$ and $\mathrm{N}^{\prime} 3$ to evaluate the filter sample homogeneity.

\begin{tabular}{|c|c|c|c|}
\hline & $\mathrm{OC}$ & $\mathrm{EC}$ & $\mathrm{TC}$ \\
\hline \multicolumn{4}{|l|}{ Filter $\mathrm{N}^{\prime} 1$} \\
\hline Mean $\left(\mu \mathrm{g} \mathrm{cm}^{-2}\right)$ & 10.0 & 3.6 & 13.6 \\
\hline Standard deviation $\left(\mu \mathrm{g} \mathrm{cm}^{-2}\right)$ & 0.6 & 0.1 & 0.7 \\
\hline Relative standard deviation (\%) & 6.1 & 3.3 & 4.8 \\
\hline \multicolumn{4}{|l|}{ Filter N'2 } \\
\hline Mean $\left(\mu \mathrm{g} \mathrm{cm}^{-2}\right)$ & 21.4 & 8.0 & 29.5 \\
\hline Standard deviation $\left(\mu \mathrm{g} \mathrm{cm}^{-2}\right)$ & 0.5 & 0.3 & 0.5 \\
\hline Relative standard deviation (\%) & 2.2 & 3.5 & 1.9 \\
\hline \multicolumn{4}{|l|}{ Filter N’3 } \\
\hline Mean $\left(\mu \mathrm{g} \mathrm{cm}^{-2}\right)$ & 27.5 & 8.3 & 35.8 \\
\hline Standard deviation $\left(\mu \mathrm{g} \mathrm{cm}^{-2}\right)$ & 0.6 & 0.2 & 0.7 \\
\hline Relative standard deviation (\%) & 2.3 & 2.7 & 1.9 \\
\hline
\end{tabular}

explained by its lowest $\mathrm{PM}_{10}$ filter loading. All results concerning homogeneity tests are given in Table 2 . The calculated RSD will be taken into account to interpret the results obtained for each laboratory.

The filters were stored in a freezer before sample punching. The punches were sent to the participants in closed Petri slides under refrigerated conditions (below $4^{\circ} \mathrm{C}$ ). Details of the planning of this interlaboratory comparison exercise are given in the Supplement. 


\subsubsection{Statistical results processing}

Within the process of interlaboratory exercises, $Z$ scores are usually calculated to evaluate the capability of a laboratory to comply with the data quality objective (DQO) of the measurements, as reported in the International Standard ISO 5725-2 (1994). However, the number of participants in this particular exercise was not sufficient to implement such a procedure. To deal with the results provided by the five laboratories, only repeatability standard deviation $\left(S_{r j}\right)$ for a laboratory $j$, the interlaboratory standard deviation $\left(S_{L j}\right)$ for a laboratory $j$, the reproducibility standard deviation for the laboratory $j$, summing both $S_{r j}$ and $S_{L j}$ and the overall uncertainty (corresponding to twice the reproducibility) were calculated. The formulae used for these calculations are provided in the Supplement.

Throughout the paper, the thermal-optical method is referred to as "EC-OC" and the ratio between EC and TC is written as EC/TC. The latter parameter is used to investigate discrepancies related to various optical corrections.

\subsection{Results}

\subsubsection{TC, EC, OC and EC/ TC individual results}

Figure 1 shows the statistical distribution (mean and standard deviation SD) for the TC and EC / TC data sets obtained by the five laboratories while Table 3 gives the mean concentration, the standard deviation, the repeatability relative standard deviation calculated for OC, EC, TC, and EC/TC for each laboratory and each filter test material. For laboratory 3 , results are given for both reflectance and transmittance within Table 3.

For sample N1, laboratories 1 and 5 obtained a very satisfactory repeatability of about $1 \%$ for TC, whereas for other laboratories the repeatability of the TC measurement was between 5 and $7 \%$, which remains satisfactory considering the low TC loading $\left(\sim 19 \mu \mathrm{g} \mathrm{cm}^{-2}\right)$ and possible related sample inhomogeneity. As to the EC/ TC ratio, laboratory 1 found substantially higher values but a lower dispersion compared to laboratories 2,3 , and 4 , whereas laboratory 5 was in between, suggesting that the differences cannot be clearly attributed, either to the analyser or to the thermal-optical protocol.

For sample N2, the TC and OC measurement repeatability values remain low $(<10 \%)$, but the repeatability of the EC and EC/TC data reaches values as high as $17 \%$. This dispersion may be related to the high EC filter loading $\left(\sim 18.6 \mu \mathrm{g} \mathrm{cm}^{-2}\right)$, as will be discussed in Sect. 5. For this specific sample N2, laboratory 2, which applies a hightemperature protocol and short durations of the temperature plateaus (NIOSH), obtained the lowest EC value of all laboratories. This is similar to results from Chow et al. (2004) who analysed the same samples with NIOSH 5040 and
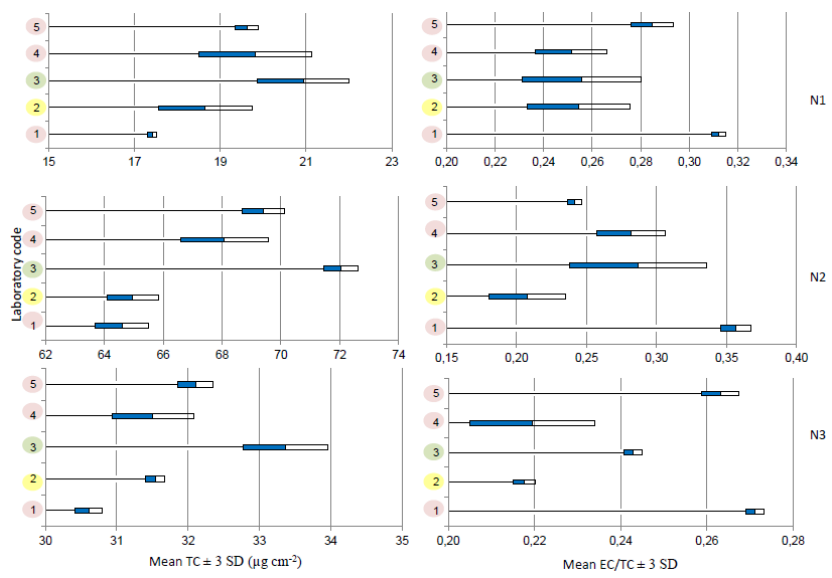

Figure 1. Statistical distribution for TC (on the left) and the EC / TC ratio (on the right). The width of each box indicates the standard deviation, while the separation between blue and white bars in the boxes represents the general mean obtained by each laboratory for the different filters. The straight black lines are meaningless and drawn to facilitate the reading only. In the present case, TOT correction was used by each laboratory.

IMPROVE protocols, the latter one using the longest temperature plateaus.

Considering sample N3, the results are similar to those for sample N1 in terms of repeatability and reproducibility.

For all filters, laboratory 3 obtained slightly higher TC values compared to the other laboratories (about $8 \%$ on average), which could be due to an erroneous concentration of the standard solution used for external calibration or erroneous volumes used for this calibration.

\subsubsection{Correlation between laboratory results (for EC and OC)}

Figure 2 shows the results of a one-way ANOVA test aiming at comparing laboratories by pair in order to determine whether some are statistically different from the others. Two figures are provided. One corresponds to the results of laboratory 3 given in transmittance while the other is for results given in reflectance. When all the results are given in transmittance, no laboratory distinguishes itself from the others. However, when the reflectance results are used for laboratory 3 , much higher EC and lower OC concentrations are obtained compared to the other laboratories. Such differences between optical corrections have already been observed within previous studies (Chow et al., 2001, 2004; Schmid et al., 2001; Schauer et al., 2003; Chen et al., 2004; Cheng et al., 2011). The different optical configurations of the DRI and Sunset instruments used here could be partly responsible for these discrepancies. Indeed, illumination of the sample filter or detection of scattered light from different angles may alter measurements (Chen et al., 2004). More insights into TOT and TOR differences are given in Sect. 3. Since laboratory 
Table 3. Mean, standard deviation (SD), repeatability relative standard deviation calculated for OC, EC, TC and EC/TC ratio for each laboratory and each filter (N1, N2 and N3).

\begin{tabular}{|c|c|c|c|c|c|c|c|c|c|c|c|c|c|}
\hline & \multirow[b]{2}{*}{ Lab Code } & \multicolumn{3}{|c|}{$\mathrm{OC}$} & \multicolumn{3}{|c|}{$\mathrm{EC}$} & \multicolumn{3}{|c|}{$\mathrm{TC}$} & \multicolumn{3}{|c|}{$\mathrm{EC} / \mathrm{TC}$} \\
\hline & & Mean $\mu \mathrm{g} \mathrm{cm}^{-2}$ & $\mathrm{SD} \mu \mathrm{g} \mathrm{cm}^{-2}$ & $\mathrm{CVr}$ & Mean $\mu \mathrm{g} \mathrm{cm}^{-2}$ & $\mathrm{SD} \mu \mathrm{g} \mathrm{cm}^{-2}$ & $\mathrm{CVr}$ & Mean $\mu \mathrm{g} \mathrm{cm}^{-2}$ & $\mathrm{SD} \mu \mathrm{g} \mathrm{cm}^{-2}$ & $\mathrm{CVr}$ & Mean $\mu \mathrm{g} \mathrm{cm}^{-2}$ & $\mathrm{SD} \mu \mathrm{g} \mathrm{cm}^{-2}$ & $\mathrm{CV}_{\mathrm{r}}$ \\
\hline \multirow[t]{5}{*}{ N1 } & 1 & 11.98 & 0.03 & $0 \%$ & 5.44 & 0.08 & $1 \%$ & 17.41 & 0.11 & $1 \%$ & 0.312 & 0.0029 & $0.9 \%$ \\
\hline & 4 & 14.84 & 1.23 & $8 \%$ & 4.97 & 0.22 & $4 \%$ & 19.81 & 1.31 & $7 \%$ & 0.254 & 0.0210 & $8.3 \%$ \\
\hline & $3^{*}$ & 15.59/13.61 & $1.26 / 1.18$ & $8 \% / 9 \%$ & $5.34 / 7.32$ & $0.35 / 0.29$ & $6 \% / 4 \%$ & 20.93 & 1.08 & $5 \%$ & $0.256 / 0.350$ & $0.024 / 0.0243$ & $9.5 \% / 6.9 \%$ \\
\hline & 2 & 13.92 & 1.21 & $9 \%$ & 4.73 & 0.15 & $3 \%$ & 18.65 & 1.09 & $6 \%$ & 0.251 & 0.0146 & $5.8 \%$ \\
\hline & 5 & 14.03 & 0.09 & $1 \%$ & 5.59 & 0.24 & $4 \%$ & 19.62 & 0.27 & $1 \%$ & 0.285 & 0.0087 & $3.0 \%$ \\
\hline \multirow[t]{5}{*}{ N2 } & 1 & 41.58 & 0.87 & $2 \%$ & 23.02 & 0.78 & $3 \%$ & 64.60 & 0.90 & $1 \%$ & 0.356 & 0.0107 & $3.0 \%$ \\
\hline & 4 & 48.90 & 2.22 & $5 \%$ & 19.18 & 1.60 & $8 \%$ & 68.08 & 1.49 & $2 \%$ & 0.208 & 0.0270 & $13.0 \%$ \\
\hline & $3^{*}$ & $51.39 / 36.70$ & $3.84 / 2.53$ & $8 \% / 8 \%$ & $20.65 / 35.34$ & 3.45/3.12 & $17 \% / 9 \%$ & 72.04 & 0.59 & $1 \%$ & $0.287 / 0.49$ & $0.0492 / 0.039$ & $17.2 \% / 8.0 \%$ \\
\hline & 2 & 51.47 & 1.75 & $3 \%$ & 13.49 & 1.81 & $13 \%$ & 64.96 & 0.87 & $1 \%$ & 0.282 & 0.0243 & $8.6 \%$ \\
\hline & 5 & 52.67 & 0.85 & $2 \%$ & 16.75 & 0.25 & $1 \%$ & 69.42 & 0.72 & $1 \%$ & 0.241 & 0.0051 & $2.1 \%$ \\
\hline \multirow[t]{5}{*}{ N3 } & 1 & 22.31 & 0.08 & $0 \%$ & 8.30 & 0.12 & $1 \%$ & 30.61 & 0.19 & $1 \%$ & 0.271 & 0.0021 & $0.8 \%$ \\
\hline & 4 & 24.59 & 0.86 & $3 \%$ & 6.91 & 0.36 & $5 \%$ & 31.51 & 0.58 & $2 \%$ & 0.218 & 0.0026 & $1.2 \%$ \\
\hline & $3^{*}$ & $25.27 / 18.41$ & $0.39 / 1$ & $2 \% / 5 \%$ & $8.10 / 14.96$ & $0.21 / 0.6$ & $3 \% / 4 \%$ & 33.37 & 0.59 & $2 \%$ & $0.243 / 0.448$ & $0.0021 / 0.231$ & $0.9 \% / 5.1 \%$ \\
\hline & 2 & 24.67 & 0.17 & $1 \%$ & 6.86 & 0.07 & $1 \%$ & 31.54 & 0.13 & $0 \%$ & 0.220 & 0.0145 & $6.6 \%$ \\
\hline & 5 & 23.66 & 0.32 & $1 \%$ & 8.44 & 0.08 & $1 \%$ & 32.10 & 0.25 & $1 \%$ & 0.263 & 0.0044 & $1.7 \%$ \\
\hline
\end{tabular}
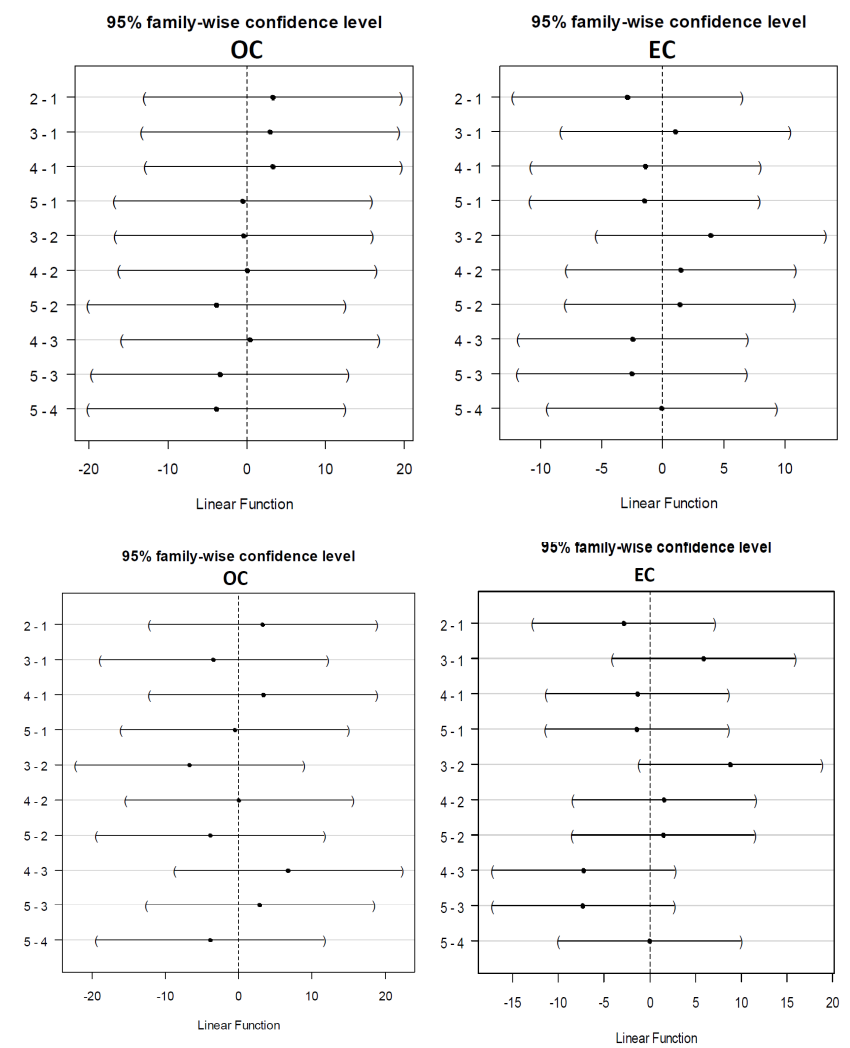

Figure 2. One-way ANOVA test to compare laboratory pairs for OC and EC measurement. Top graphs contain results from laboratory 3 in transmittance. Bottom graphs contain results from laboratory 3 in reflectance.

3 provided both TOT and TOR results, EC and OC concentrations obtained using TOT charring correction will be considered in the following discussion for comparison with the other four laboratories.

\subsubsection{Overall reproducibility and repeatability}

Table 4 presents the overall results obtained for each filter (N1, N2 and N3), comprising the mean concentration of all laboratories $\left(\mu \mathrm{g} \mathrm{cm}^{-2}\right)$, the standard deviation $\left(\mu \mathrm{g} \mathrm{cm}^{-2}\right)$, the interlaboratory reproducibility (corresponding to the ratio between the standard deviation for all laboratories and the general arithmetic mean for all laboratories) and the intralaboratory repeatability \% (corresponding to the arithmetic mean of ratio between the standard deviation obtained for each laboratory and the arithmetic mean obtained for each laboratory), and the overall uncertainty corresponding to twice the interlaboratory reproducibility $\%$ as stated in the NF EN ISO/CEI 17025 standard for TC, EC, OC and $\mathrm{EC} / \mathrm{TC}$. Despite the instrument and protocol heterogeneity, the reproducibility and repeatability for TC analysis are respectively below 7 and $4 \%$, which is similar to what has been commonly reported in the literature (Schmid et al., 2001; ten Brink et al., 2004; Park et al., 2005). The highest values of reproducibility and repeatability were obtained for filter N1 and may be explained by its lowest TC filter loading $\left(19.3 \mu \mathrm{g} \mathrm{cm}^{-2}\right)$. The repeatability and reproducibility values are higher for EC (from 6.8 to $19.7 \%$ and from 2.2 to $8.7 \%$, respectively) and OC (from 4.1 to $9.6 \%$ and from 1.5 to $5.2 \%$, respectively) and consequently for the $\mathrm{EC} / \mathrm{TC}$ ratio too. The least satisfactory results regarding reproducibility and repeatability standard deviations are obtained for EC in sample N2. This could be related to the high EC filter loading $\left(\sim 19 \mu \mathrm{g} \mathrm{cm}^{-2}\right)$, as discussed in what follows.

Finally, for a given thermal protocol, the differences observed between the laboratories have to be primarily attributed to the lack of temperature offset calibration by the time of the analyses, as a deviation of the front oven temperature from the set temperature may lead to a shift of EC/ TC. Indeed, temperatures higher than expected during the inert phase may lead to premature EC degradation, while temperatures lower than expected during the same phase may reduce the efficiency of $\mathrm{OC}$ volatilisation. In this respect, 
Table 4. Overall laboratory mean concentration $\left(\mu \mathrm{g} \mathrm{cm}^{-2}\right)$, standard deviation $\left(\mu \mathrm{g} \mathrm{cm}^{-2}\right)$, reproducibility and repeatability $\%$ standard deviations (\%) for TC. EC, OC and the EC/ TC ratio in samples N1, N2 and N3.

\begin{tabular}{llrrrrr}
\hline & & $\begin{array}{r}\text { Mean } \\
\text { concentration } \\
\left(\mu \mathrm{g} \mathrm{cm}^{-2}\right)\end{array}$ & $\begin{array}{r}\text { Standard } \\
\text { deviation } \\
\left(\mu \mathrm{g} \mathrm{cm}^{-2}\right)\end{array}$ & $\begin{array}{r}\text { Reproducibility } \\
\text { s.d. }(\%)\end{array}$ & $\begin{array}{r}\text { Overall } \\
\text { Repeatability } \\
\text { s.d. }(\%)\end{array}$ & $\begin{array}{r}\text { Uncertainty } \\
(\%)\end{array}$ \\
\hline $\mathrm{N} 1 \quad$ TC & 19.28 & 1.32 & 6.9 & 3.9 & 14 \\
& EC & 5.21 & 0.35 & 6.8 & 3.9 & 14 \\
& OC & 14.07 & 1.35 & 9.6 & 5.2 & 19 \\
& EC/TC & 0.27 & 0.03 & 9.7 & 5.5 & 19 \\
\hline $\mathrm{N} 2$ & TC & 67.82 & 3.12 & 4.6 & 1.4 & 9 \\
& EC & 18.62 & 3.66 & 19.7 & 8.7 & 39 \\
& OC & 49.2 & 4.48 & 9.1 & 3.8 & 18 \\
& EC/TC & 0.27 & 0.06 & 20.3 & 8.8 & 40 \\
\hline N3 & TC & 31.82 & 1.02 & 3.2 & 1.1 & 6 \\
& EC & 7.72 & 0.77 & 10 & 2.2 & 20 \\
& OC & 24.1 & 1.15 & 4.8 & 1.5 & 10 \\
& EC/TC & 0.24 & 0.02 & 10.1 & 2.2 & 20 \\
\hline
\end{tabular}

Sunset Laboratory Inc. nowadays provides a toolkit dedicated to the correction of the drift of the front oven temperature probe, which was not available when the intercomparison presented above was conducted. This toolkit was distributed in July 2012 to some European laboratories, including the ones that used the EUSAAR-2 protocol within the present intercomparison exercise. These three laboratories could then investigate the temperature offsets for their instrument. As presented in Table 5, the more important this temperature offset for the last step under He, the higher the EC / TC that was obtained. This might be explained by a lack of volatilisation of the most refractory OC species under the He phase when the temperature of the front oven is significantly lower than expected. However, in the particular case of filter N2 (exhibiting the highest EC and OC loadings), laboratory 5 obtained a lower EC/ TC than laboratory 4, while the latter one presented a less pronounced temperature offset. It thus appears that another parameter may contribute to the discrepancies observed for EC/TC. This additional parameter might be the apparent laser signal intensity, which also seems to correlate with EC/ TC in particular for filter N2 (Table 5).

\subsubsection{Conclusions on the interlaboratory comparison exercise}

Several conclusions can be drawn from this first French interlaboratory comparison study:

- Whatever the analytical protocol (NIOSH 5040, IMPROVE or EUSAAR-2), the repeatability for each laboratory is satisfactory, with a corresponding standard deviation for TC, OC and EC being mostly below $10 \%$ for the three test filters.
- As previously reported in the literature (Chow et al., 2001, 2004; Schmid et al., 2001; Schauer et al., 2003; Chen et al., 2004; Cheng et al., 2011), the differences between results obtained with a charring correction based on transmittance or reflectance for the same thermal protocol (the IMPROVE protocol in our case) is significant, $\mathrm{OC}_{\mathrm{TOT}}$ being about $30 \%$ higher than $\mathrm{OC}_{\mathrm{TOR}}$ and $\mathrm{EC}_{\mathrm{TOT}}$ being about $50 \%$ lower than $\mathrm{EC}_{\mathrm{TOR}}$.

- When considering TOT results only, the overall uncertainty of the mean TC, OC and EC concentrations among the five laboratories ranges from 6 to $39 \%$, with the mean uncertainties being 10, 16 and $29 \%$, respectively.

- The carbon filter loading seems to have an impact on the data quality: higher loadings lead to poorer results for the reproducibility of the EC measurement among the laboratories. Also, a low TC loading may lead to less satisfactorily repeatable results. It is worth mentioning that for this interlaboratory comparison, the oven temperature probes were not calibrated. Since then, a calibration procedure has been implemented and another comparison should be organised.

The small number of laboratories involved in this intercomparison exercise is a clear limitation to the present study. To go deeper into the issues of charring correction (TOT or TOR), an additional study based on the comparison of reflectance and the transmittance results for OC and EC measured on about 700 filters sampled at rural, urban and suburban sites, in France, Belgium and Italy was performed and is presented below. 
Table 5. Dependence of EC/TC on the temperature offset of the front oven and/or on the laser intensity for laboratories using the same thermal protocol (EUSAAR 2).

\begin{tabular}{lrrrrr}
\hline $\begin{array}{r}\text { Temperature } \\
\text { offset for the } \\
\text { last step under } \\
\mathrm{He}\end{array}$ & $\begin{array}{r}\text { Laser } \\
\text { transmission } \\
\text { intensity for a } \\
\text { blank filter }\end{array}$ & $\begin{array}{r}\text { EC/TC for N1 } \\
\text { (mean EC } \\
\text { loading of } \\
5.2 \mu \mathrm{g} \mathrm{cm}^{-2} \text { ) }\end{array}$ & $\begin{array}{r}\text { EC/TC for N2 } \\
\text { (mean EC } \\
\text { loading of } \\
18.6 \mu \mathrm{g} \mathrm{cm}^{-2} \text { ) }\end{array}$ & $\begin{array}{r}\text { EC / TC for N3 } \\
\text { (mean EC } \\
\text { loading of } \\
7.7 \mu \mathrm{g} \mathrm{cm}^{-2} \text { ) }\end{array}$ \\
\hline Lab. 1 & -80 & 15000 & 0.31 & 0.36 & 0.27 \\
Lab. 5 & -55 & 1600 & 0.28 & 0.24 & 0.26 \\
Lab. 4 & +30 & 4400 & 0.25 & 0.28 & 0.22 \\
\hline
\end{tabular}

\section{Charring optical correction: reflectance and transmittance comparison for filter samples from different types of sites}

\subsection{Methodology}

To systematically study the differences in EC and OC measurements as a function of the optical technique implemented to correct for charring, three batches of filter samples were considered. The first one was provided by the CARA programme, and therefore sampled at the same conditions as described previously for the test filters of the French interlaboratory comparison study. The $245 \mathrm{PM}_{10}$ filters studied here were sampled in 2008 and 2009 in urban sites in northern France and analysed with the EUSAAR-2 protocol.

The second one was provided by the Flemish Environmental Agency (VMM) and analysed by Ghent University (UGent) with the NIOSH 5040 protocol. $\mathrm{PM}_{10}$ and $\mathrm{PM}_{2.5}$ were simultaneously sampled on $47 \mathrm{~mm}$ diameter Pallflex Tissuquartz 2500 QAT-UP (pre-fired in the factory) at an urban site with extensive traffic influence and at a rural background site, for $24 \mathrm{~h}$ with a low-volume sampler (Leckel SEQ47/50) running at $2.3 \mathrm{~m}^{3} \mathrm{~h}^{-1}$ flow rate. A total of 128 filters are considered in this study.

The third batch of filter samples was obtained by the EC-JRC-IES Climate Change Unit and consisted of $\mathrm{PM}_{2.5}$ samples taken in 2007 at the Ispra EMEP station (IT04). The samplings lasted $24 \mathrm{~h}$ and were performed with lowvolume samplers (Partisol 2025, Thermo Scientific) running at $1 \mathrm{~m}^{3} \mathrm{~h}^{-1}$ flow rate, on $47 \mathrm{~mm}$ diameter Pallflex 2500 QATUP. A total of 329 filters were taken and analysed with the EUSAAR-2 protocol.

The EC-OC analytical results were provided by each laboratory with both transmittance and reflectance optical correction of charring and using Sunset Laboratory Inc. analysers.

\subsection{Results}

\subsubsection{Comparison of $\mathrm{OC}$ measured with transmittance $\left(\mathrm{OC}_{\mathrm{TOT}}\right)$ and reflectance $\left(\mathrm{OC}_{\mathrm{TOR}}\right)$}

Whatever the temperature protocol or the site, the correlation between the TOR and TOT data was good with squared correlation coefficients $\left(R^{2}\right)$ ranging from 0.904 to 0.997 . However, as shown in Fig. 3, the transmittance optical correction led to higher OC values than TOR. Chow et al. (2004) have explained this pattern by the charring occurring within the filter and not only at the surface. Since transmittance correction is influenced by char present within the filter and light reflected may be absorbed or scattered by particulate matter at the filter surface, higher OC data may be expected with the TOT correction.

Compared to EUSAAR-2, the NIOSH protocol showed a larger difference between TOT and TOR. The main differences between the two protocols lie in the highest temperature step during the He mode and the shortest durations of the temperature plateaus for NIOSH 5040 (see Table 1). These two points appear to be key parameters that define the split point between EC and OC (Subramanian et al., 2006; Cavalli et al., 2010). In particular, when the last temperature step in the He mode is too low, OC is not likely to evolve completely, resulting in OC underestimation. However, for filters containing metal oxides and/or sea salts, EC may already evolve during the inert phase under high temperature (Sciare et al., 2003). Therefore, depending on the filter loading of non-carbonaceous particles, the NIOSH protocol may systematically overestimate OC compared to EUSAAR-2. In addition, as stated above, the different optical configurations could be partly responsible for these discrepancies. Interactions with the light pipe walls as well as possible drift of the laser diode could also affect measurements. Finally, the influence of these phenomena on measurements may also depend on the temperature prevailing when the split point occurs (see Sect. 4.2).

In our case, only slight differences were observed between the results of rural and urban areas, with OC TOT versus TOR ratios being only slightly higher for the rural sites in the case where the NIOSH protocol was applied. Still, for both types of sites, $\mathrm{OC}_{\mathrm{TOT}}$ remained higher than $\mathrm{OC}_{\mathrm{TOR}}$, which is consistent with the results reported by Cheng et al. (2011).

\subsubsection{Comparison of EC measured with transmittance $\left(\mathbf{E C}_{\text {TOT }}\right)$ and reflectance $\left(\mathrm{EC}_{\mathrm{TOR}}\right)$}

Although rather good, the correlation between reflectance and transmittance results was less satisfactory for EC than for 


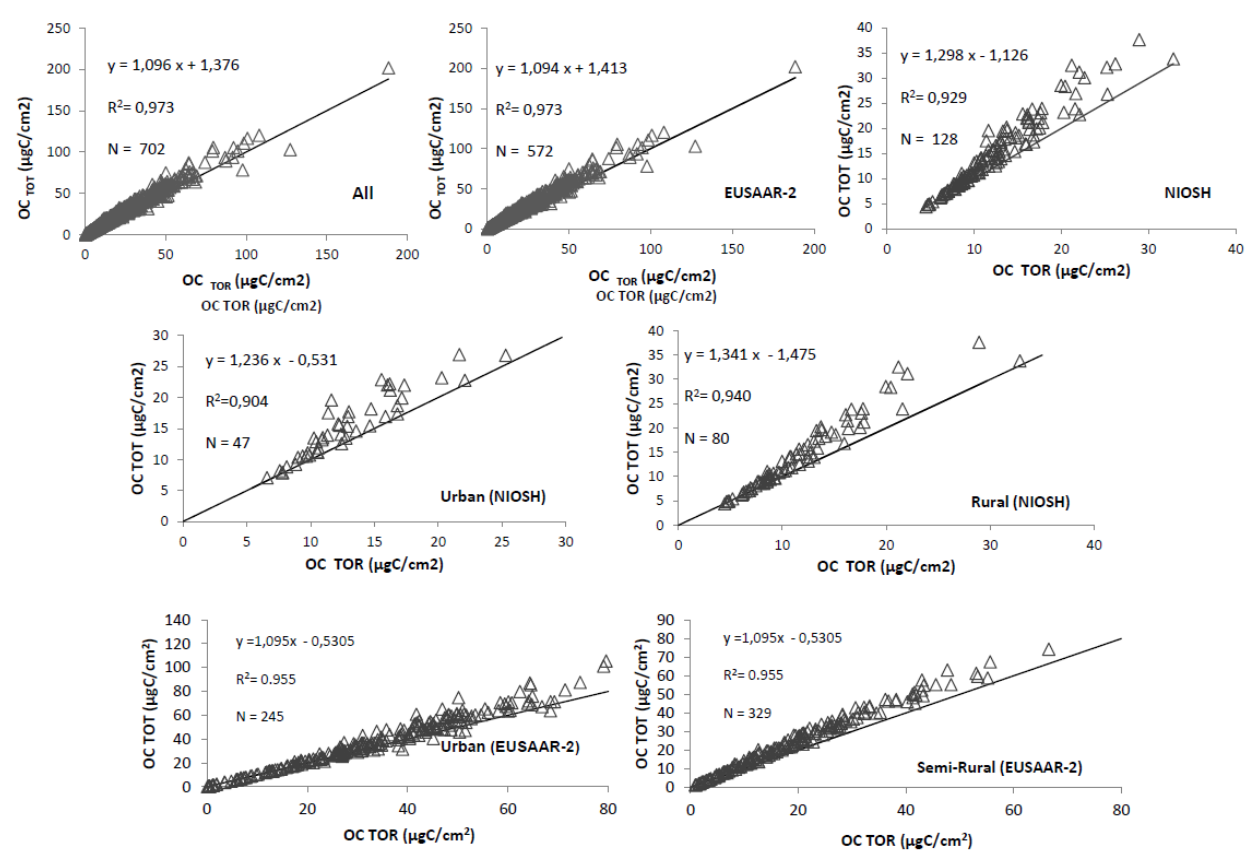

Figure 3. Comparison between reflectance and transmittance for OC for the different samples analysed using EUSAAR-2 (urban and semirural samples) or NIOSH (urban and rural samples) protocols. Slope coefficients $(y=a x+b)$, correlation coefficients $\left(R^{2}\right)$ and the number of samples $(N)$ are given for each graph.

OC, with squared correlation coefficients $\left(R^{2}\right)$ ranging here from 0.851 to 0.861. As shown in Fig. 4, measurements obtained with the transmittance optical correction led to lower EC than reflectance, as already observed by Zhi et al. (2011) and Cheng et al. (2011) comparing NIOSH and IMPROVE. Chow et al. (2004) also observed differences while varying the temperature protocol (EC data determined by simultaneous TOT correction were $30 \%$ lower than TOR data for the IMPROVE temperature protocol and 70-80\% lower for a protocol with higher heating temperatures and shorter residence times) (see Table 1).

Besides by these phenomena, the differences could be explained by the distribution of the carbonaceous material on the filter and more precisely of the light-absorbing carbon which lies mainly at the surface whereas the pyrolytic carbon is mainly present inside the filter. The reflectance signal consequently returns to its original value earlier than the transmittance one (Chow et al., 2004) leading to higher EC values. In Fig. 4, the largest differences between the TOT to TOR ratios were observed when comparing results obtained for rural and urban samples using NIOSH5040. Indeed, results obtained for rural samples displayed the lowest TOT to TOR ratio of about 0.5 in agreement with previously reported results (e.g. Cheng et al., 2011). These differences may be explained by the aerosol chemical composition or its mixing state, which can be rather different between urban and rural sites. For example, the latter could be much more influenced by light-absorbing organic material at the wavelength used within Sunset instruments $(660 \mathrm{~nm})$, such as brown carbon and/or humic-like substances (Lukacs et al., 2007). It can also arise from biomass combustion processes leading to the formation of what is called "tar balls" (Chakrabarty et al., 2010). Indeed, when comparing different techniques for black and elemental carbon, Sciare et al. (2003) and Reisinger et al. (2008) showed that a high influence of biomass burning sources led to the largest differences between the different techniques, while no differences could be observed for traffic samples (Hitzenberger et al., 2006). Furthermore, Schauer et al. (2003) indicated that the EC data of NIOSH-like and IMPROVE-like protocols (both with transmittance optical correction) exhibited larger differences for biomass burning particles than for urban ambient $\mathrm{PM}_{2.5}$ particles. Cheng et al. (2011) also compared the NIOSH and IMPROVE protocols and observed significant differences between both protocols. The differences, displaying clear seasonal and spatial variations, were found to be higher at sites where abundant SOA (Secondary Organic Aerosol) was present. This supports the evidence that SOA contributes to higher discrepancies between both protocols in summer (Yu et al., 2002).

However, the way in which brown carbon and more generally the particle chemical composition can influence the TOT and TOR correction is still not clear and needs further investigation. 


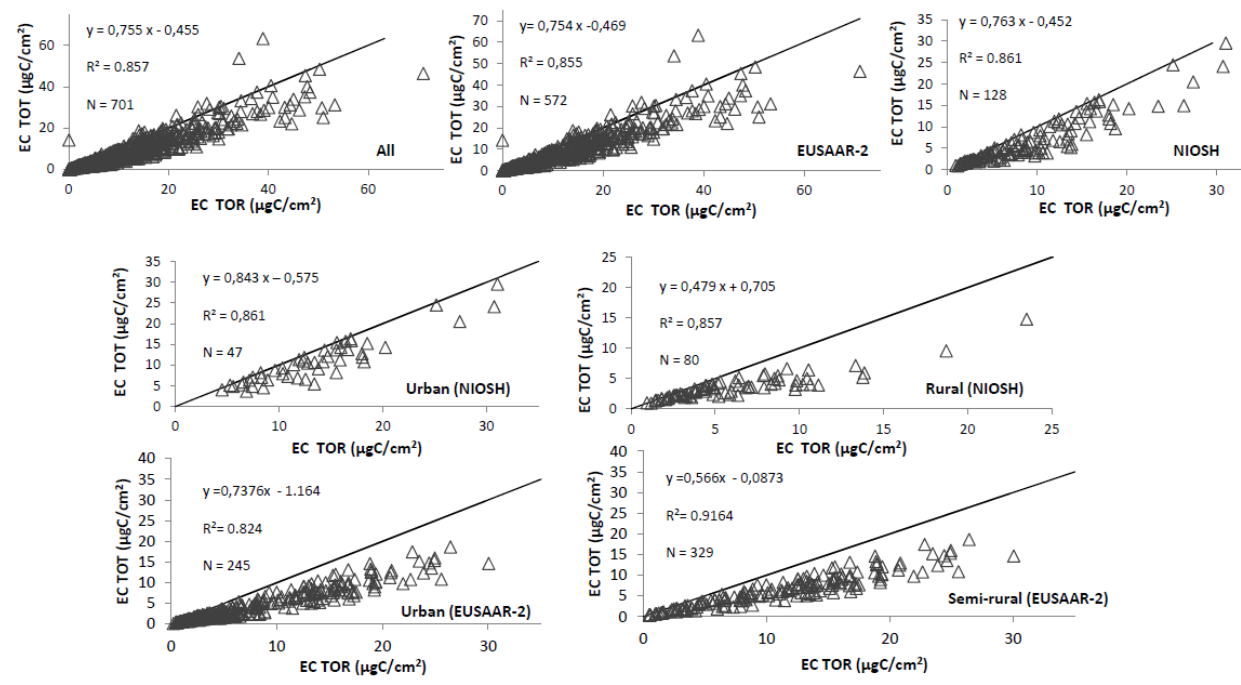

Figure 4. Comparison between reflectance and transmittance for EC for the different samples analysed using EUSAAR-2 (urban and semirural samples) or NIOSH (urban and rural samples) protocols. Slope coefficients $(y=a x+b)$, correlation coefficients $\left(R^{2}\right)$ and the number of samples $(N)$ are given for each graph.

\section{Laser signal intensity}

\subsection{Methodology}

The apparent laser signal transmission or reflectance intensity decreases generally with the number of analyses due to the soiling of the front oven. A decrease of the laser intensity may also be enforced by adjusting the laser potentiometer setting. However, in the latter experiment, the increase of light scattering due to clusters deposited or formed at the inner surface of the oven is not taken into account. In order to distinguish between the latter effect and the one due to a pure laser signal decrease, we set up an experiment in which measurements were conducted just before and just after the replacement of a soiled oven. In this experiment, 20 samples from various locations in France (mainly $\mathrm{PM}_{10}$ samples collected at urban background sites) were analysed in the following three conditions:

1. With a soiled oven (oven 1) and for a laser transmission signal intensity for blank filters of 3000 . It should be emphasised that this oven exhibited a very significant soiling, due to previous analyses of samples containing large amounts of sea salt, samples containing large amounts of Saharan dust, as well as samples collected in the plume of woodstoves. The soiling was observed in the form of a white circle at the place where the laser signal enters the oven. This experiment can therefore be seen as an "extreme case".

2. With a brand new and clean oven (oven 2) for the same laser transmission signal intensity for blank filters of 3000.
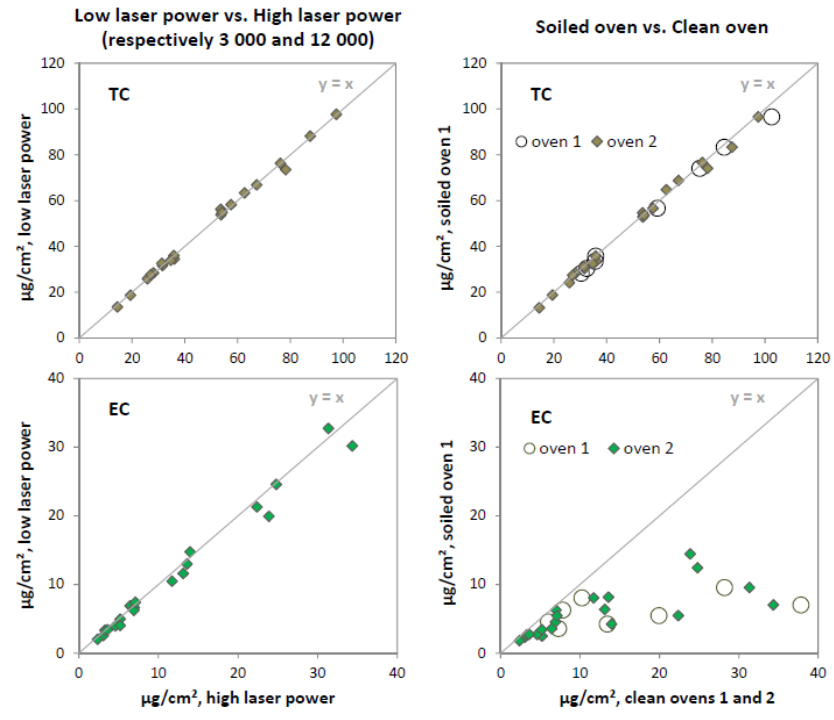

Figure 5. Influence of the laser power (for a clean oven, left panel) and of the oven soiling (extreme case, right panel) on EC measurements.

3. With the same new oven, but for a laser transmission signal intensity for blank filters of 12000 .

In fact, 7 of the 20 tested samples had already been analysed with oven 1 just after its setting up (i.e. when it was quite clean).

\subsection{Results}

The results of the experiment are shown in Fig. 5, allowing for the comparison of TC and EC data obtained for (i) two 


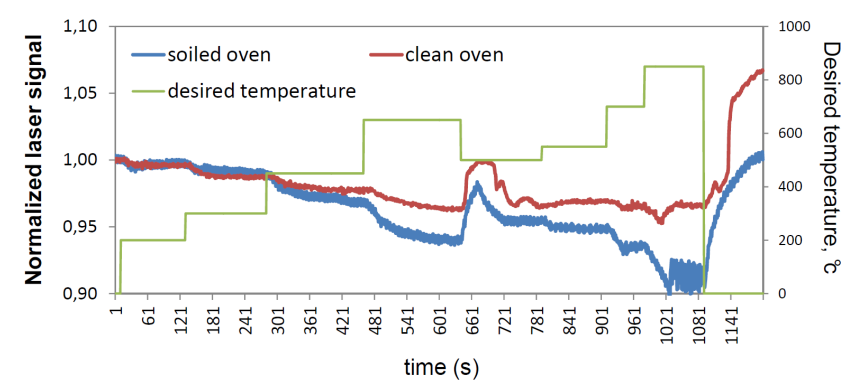

Figure 6. Time evolution of the laser transmission signal intensity during instrumental blank analysis with a clean and a soiled oven, using a Sunset Lab. analyser. For comparison purposes, the laser signals have been normalised to their initial value.

different laser signal intensities when using a clean oven and (ii) soiled versus clean ovens. The very good agreement obtained for TC in both comparisons enforces the consistency of the EC data.

It appears that only decreasing the laser intensity from 12000 to 3000 has no significant impact on the EC concentration. In contrast, EC concentrations obtained with the soiled oven are significantly lower (up to a factor of 4) than the ones obtained with the clean ovens. This phenomenon might be explained by the influence of the front oven temperature on the laser signal. Indeed, a slight decrease of transmission is generally observed with increasing temperature, which could be observed for instance for an instrumental blank (using a blank filter resulting from a previous analysis). As shown in Fig. 6, the oven soiling induces an additional light scattering and a decrease of the laser baseline, which could generate a bias in the split point determination leading to an underestimation of the EC content.

As shown in Fig. 7a, the largest differences were obtained for samples containing the highest EC loadings and presenting the highest contents of OC pyrolysed during analysis. These samples were actually collected during wintertime and probably contained high amounts of brown carbon emitted from biomass burning. Similar results were obtained for a second data set corresponding to 16 samples collected at Belgian traffic sites and analysed using the NIOSH protocol and two different ovens: a dirty oven with an apparent laser transmission signal intensity of approximately 4000 and a clean new oven (Fig. 7b).

It thus appears that the use of soiled ovens may lead to an underestimation of EC concentrations, especially for samples containing high loadings of EC and brown carbon. However, the limited number of data available for the present study, as well as the lack of systematic temperature offsets calibration before each batch of analyses, prevent making any definitive conclusions and could only call for more investigations.

The same statement may be made for the influence of the decrease of the laser light transmission intensity when only caused by adjusting the laser power. Indeed, the results

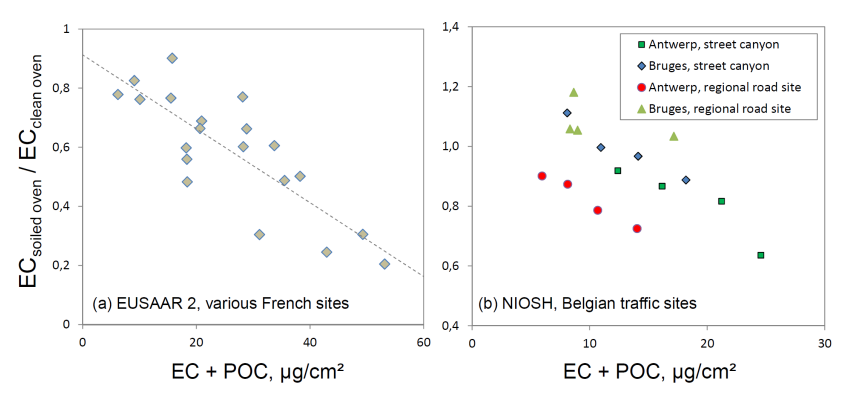

Figure 7. Ratios of EC concentrations obtained when using clean and soiled (extreme case) ovens as a function of the EC + POC filter loading using the EUSAAR 2 (a) and NIOSH (b) thermal protocols.

presented above are only based on the comparison between two laser signal intensities and one may wonder whether a lower intensity (e.g. around or below 1000) would also have no impact on the measurements. In particular, the analysis of highly loaded samples using a weak laser power will lead to a very low initial laser transmission signal intensity, which may generate a bias in the split point determination. This phenomenon also needs investigation.

\section{Influence of the EC loading}

The potential influence of the EC concentration on the ECOC measurement quality was examined with two different experiments designed to load quartz fibre filters with increasing EC amounts. The first experiment involved the use of a propane burner (LNI Schmidlin SA) in order to load filters with different amounts of "pure" EC. Since it is not simple to generate a known and controlled amount of particles with such a burner, different EC filter loadings were obtained varying the sampling time and simultaneously using two low-volume $\mathrm{PM}_{2.5}$ samplers (Partisol 2025, Thermo Scientific): a single filter was collected using one sampler while the second sampler was used to collect soot on several consecutive filters. For the latter sampler, the number of samples depended on the total sampling time performed with the first sampler (typically one filter every $10 \mathrm{~min}$ ). Seven different sampling times were tested this way. The surface EC content (in $\mu \mathrm{g} \mathrm{cm}^{-2}$ ) measured on the filters collected using the first sampler was systematically compared to the sum of the surface EC contents measured on the filters collected using the second sampler. Very low contents of OC $(\mathrm{EC} / \mathrm{OC}>0.9)$ were obtained on these filters. Then, in a second step, ten microlitres of a $2 \mathrm{gC} \mathrm{L}^{-1}$ glucose solution (corresponding to $20 \mu \mathrm{g} \mathrm{cm}^{-2}$ of OC deposited on the filter) was spiked on the filter punches in order to reproduce as much as possible a real carbonaceous PM content. Seven EC levels, ranging from 4 to $38 \mu \mathrm{g} \mathrm{cm}^{-2}$, were tested. As presented in Fig. 8a, a very good agreement was obtained when directly comparing EC concentrations obtained from the two sampling devices. The addition of glucose a posteriori on 


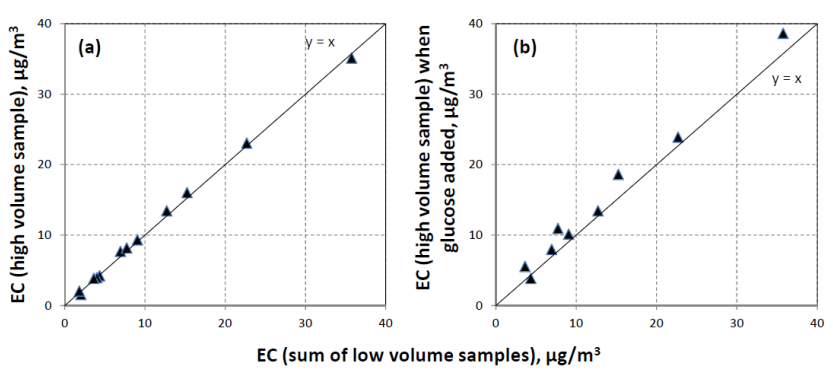

Figure 8. Comparison between EC measured on high-volume samples and EC calculated as the sum of low-volume samples. (a) EC only; (b) EC plus glucose spiked on the filters.

long-time duration samples led to a less satisfactory correlation (Fig. 8b), suggesting an increase of the uncertainty due to the enhanced influence of charring. However, despite this uncertainty increase, no significant systematic influence of EC loading could be observed.

The second experiment was performed on real ambient particles (collected during late summer at a peri-urban background site) and involved the use of two high-volume samplers (Digitel DA80) to simultaneously sample $\mathrm{PM}_{2.5}$ with various sampling times. Using one of these samplers, four sampling durations were tested: (i) three filters sampled for $24 \mathrm{~h}$, (ii) one filter sampled for $48 \mathrm{~h}$, (iii) two filters sampled for $72 \mathrm{~h}$ and (iv) one filter sampled for $120 \mathrm{~h}$. For each set of sampling times, the other high-volume sampler covered the same period with filters collected every $24 \mathrm{~h}$. Therefore, $24 \mathrm{~h}$ filter samples were compared to $24 \mathrm{~h}$ filter samples, $48 \mathrm{~h}$ filter samples were compared to two $24 \mathrm{~h}$ filter samples, and $120 \mathrm{~h}$ samples sere compared to five $24 \mathrm{~h}$ samples. As presented in Fig. 9, both EC and OC measurements actually displayed the same tendency: the differences between the sum of $24 \mathrm{~h}$ samples and the long-time samples (48, 72 and $120 \mathrm{~h})$ depend on the sampling duration, with higher differences for both EC and OC for longer experiments. This cannot be attributed to between-sample biases, as no significant differences were obtained for each one of the three $24 \mathrm{~h}$ sampling time tests (when samplings corresponded to only one filter per sampler). Alternatively, for OC, the highest concentrations derived from the sum of $24 \mathrm{~h}$ samples are consistent with the increasing positive organic adsorption artifact with decreasing sampling time and the increasing negative artifact with increasing sampling time, as shown by Kirchstetter et al. (2001). Similar results obtained for EC seem to indicate that semi-volatile organics involved in positive/negative sampling artifacts could influence the determination of the EC concentration. It might also be hypothesised that higher loadings of scattering material (e.g. ammonium sulfate) on filters of longer sampling duration have a similar effect than the soiling of the oven, i.e. a possible decrease of the EC/ TC ratio (see Sect. 4).

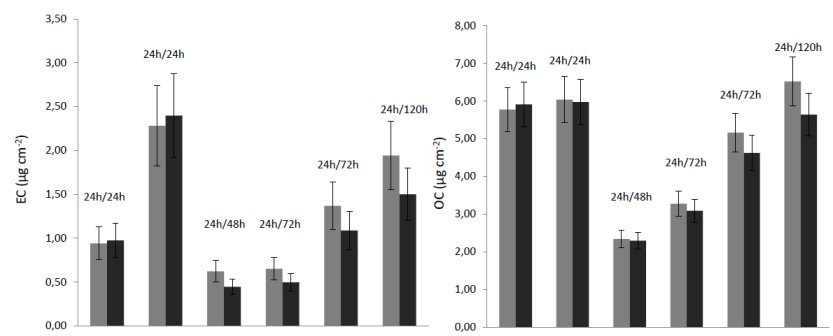

Figure 9. Comparison of EC and OC concentrations for different lengths of sampling time. Error bars correspond to 20 and $10 \%$ uncertainty for EC and OC, respectively.

\section{Conclusions}

Different analytical protocols have been widely used for many years to determine EC and OC in aerosols. The thermal-optical method is nowadays considered by the US and European normalisation works as a reference methodology to quantify EC-OC. However, the comparison between various thermal-optical methods still results in significant differences. This work has aimed at providing information on some parameters influencing these differences. Two major conclusions are presented here:

1. There are larger differences between $\mathrm{OC}_{\mathrm{TOT}}$ and $\mathrm{OC}_{\mathrm{TOR}}$ measured with NIOSH in comparison to EUSAAR-2. Significant differences between $\mathrm{EC}_{\mathrm{TOT}} / \mathrm{EC}_{\mathrm{TOR}}$ ratios can also be observed when comparing rural and urban results: at rural sites, $\mathrm{EC}_{\mathrm{TOT}}$ is $50 \%$ lower than $\mathrm{EC}_{\mathrm{TOR}}$ whereas it is $20 \%$ lower at urban sites. The PM chemical composition could explain these differences, but the way in which it influences the EC-OC measurement is not clear and needs further investigation.

2. The EC/ TC ratio seems to decrease when a soiled oven is used. At this point, no threshold value may be definitely proposed for the laser signal intensity, and the present study can only call for further investigation. However, it is strongly recommended to use a large test filter to track long-term changes in charring correction in the course of day-to-day analyses.

These results provide insights to determine the accuracy of EC-OC analytical methods and certainly contribute to the work which has to be done to establish method standardisation.

The Supplement related to this article is available online at doi:10.5194/amt-7-1649-2014-supplement. 
Acknowledgements. This work was supported by the French Ministry of the Environment. The authors also wish to acknowledge Air Normand, Atmo Nord Pas de Calais and the Flemish Environmental Agency (VMM) for filter sampling.

Very sadly, Laura Chiappini passed away a couple of weeks after the initial submission of this paper. All co-authors extend their sympathy to her family. They also warmly acknowledge her for the intensive effort she devoted to the present study, for which she was mainly responsible.

Edited by: P. Herckes

\section{References}

Birch, M. E. and Cary, R. A.: Elemental carbon based method for monitoring occupational exposure to particulate diesel exhaust, Aerosol Sci. Technol., 25, 221-241, 1996.

Cavalli, F., Viana, M., Yttri, K. E., Genberg, J., and Putaud, J.-P.: Toward a standardised thermal-optical protocol for measuring atmospheric organic and elemental carbon: the EUSAAR protocol, Atmos. Meas. Tech., 3, 79-89, doi:10.5194/amt-3-79-2010, 2010.

Chakrabarty, R. K., Moosmüller, H., Chen, L.-W. A., Lewis, K., Arnott, W. P., Mazzoleni, C., Dubey, M. K., Wold, C. E., Hao, W. M., and Kreidenweis, S. M.: Brown carbon in tar balls from smoldering biomass combustion, Atmos. Chem. Phys., 10, 63636370, doi:10.5194/acp-10-6363-2010, 2010.

Chen, L. W. A., Chow, J. C., Watson, J. G., Moosmüller, H., and Arnott, W. P.: Modeling reflectance and transmittance of quartzfiber filter samples containing elemental carbon particles: Implications for thermal/optical analysis, J. Aerosol Sci., 35, 765-780, 2004.

Cheng, Y., Zheng, M., He, K.-B., Chen, Y., Yan, B., Russell, A. G., Shi, W., Jiao, Z., Sheng, G., Fu, J., and Edgerton, E. S.: Comparison of two thermal-optical methods for the determination of organic carbon and elemental carbon: Results from the southeastern United States, Atmos. Environ., 45, 1913-1918, 2011.

Chiappini, L., Bessagnet, B., Marchand, N., Abidi, E., Verlhac, S., and Aymoz, G.: The French network organisation for PM episodes comprehension: chemical speciation, CHIMERE modelling and source apportionment, International Aerosol Conference (IAC), Helsinki, Finland, 2010.

Chow, J. C., Watson, J. G., Pritchett, L. C., Pierson, W. R., Frazier, C. A., and Purcell, R. G.: The DRI thermal/optical reflectance carbon analysis system: description, evaluation and applications in U.S. air quality studies, Atmos. Environ., 27A, 1185-1201, 1993.

Chow, J. C., Watson, J. G., Crow, D., Lowenthal, D. H., and Merrifield, T.: Comparison of IMPROVE and NIOSH carbon measurements Aerosol Sci. Technol., 34, 23-34, 2001.

Chow, J. C., Watson, J. G., Chen, L. W. A., Arnott, W. P., Moosmüller, H., and Fung, K.: Equivalence of elemental carbon by thermal/optical reflectance and transmittance with different temperature protocols, Environ. Sci. Technol., 38, 4414-4422, 2004.

Colette, A., Favez, O., Meleux, F., Chiappini, L., Haeffelin, M., Morille, Y., Malherbe, L., Papin, A., Bessagnet, B., Menut, L., Leoz, E., and Rouil, L.: Assessing in near real time the impact of the April 2010 Eyjafjallajokull ash plume on air quality, Atmos.
Environ., 45, 1217-1221, doi:10.1016/j.atmosenv.2010.09.064, 2010.

Dod, R. L., Rosen, H., and Novakov, T.: Atmospheric Aerosol Research: Annual Report 1977-78, Lawrence Berkeley Laboratory, Berkeley, California LBL-8696, 2-10, 1978.

Hitzenberger, R., Petzold, A., Bauer, H., Ctyroky, P., Pouresmaeil, P., Laskus, L., and Puxbaum, H.: Intercomparison of thermal and optical measurement methods for elemental carbon and black carbon at an urban location, Environ. Sci. Technol., 40, 63776383, 2006.

Huntzicker, J. J., Johnson, R. L., Shah, J. J., and Cary, R. A.: Analysis of organic and elemental carbon in ambient aerosols by a thermal-optical method, in: Particulate carbon: Atmospheric life cycle, edited by: Wolff, G. T. and Klimisch, R. L., Plenum, NewYork, 79-88, 1982.

ISO 5725-2: Application of statistics - Accuracy (trueness and precision) of measurement method and results - Part 2: basic method for the determination of repeatability and reproducibility of a standard measurement method, 1994.

Johnson, R. L. and Huntzicker, J. J.: Proceedings: Carbonaceous Particles in the Atmosphere, Lawrence Berkeley Laboratory, edited by: Novakov, T., 10-13, 1979.

Kahnert, M., Lazaridis, M., Tsyro, S., and Torseth, K.: Requirements for developing a regional monitoring capacity for aerosols in Europe within EMEP, J. Environ. Monitor., 6, 646-655, 2004.

Kirchstetter, T. W., Corrigan, C. E., and Novakov, T.: Laboratory and field investigation of the adsorption of gaseous organic compounds onto quartz filters, Atmos. Environ., 35, 1663-1671, 2001.

Lukacs, H., Gelencser, A., Hammer, S., Puxbaum, H., Pio, C., Legrand, M., Kasper-Giebl, A., Handler, M., Limbeck, A., Simpson, D., and Preunkert, S.: Seasonal trends and possible sources of brown carbon based on 2-year aerosol measurements at six sites in Europe, J. Geophys. Res., 112, D23S18, doi:10.1029/2006JD008151, 2007.

Park, S. S., Bae, M. S., Schauer, J. J., Ryu, S. Y., Kim, Y. J., Yong Cho, S., and Kim, S. J.: Evaluation of the TMO and TOT methods for OC and EC measurements and their characteristics in $\mathrm{PM}_{2.5}$ at an urban site of Korea during ACE-Asia, Atmos. Environ., 39, 5101-5112, 2005.

Reisinger, P., Wonaschütz, A., Hitzenberger, R., Petzold, A., Bauer, H., Jankowski, N., Puxbaum, H., Chi, X., and Maenhaut, W.: Intercomparison of measurement techniques for black or elemental carbon under urban background conditions in wintertime: Influence of biomass combustion, Environ. Sci. Technol., 42, 884889, 2008.

Schauer, J. J., Mader, B. T., DeMinter, J. T., Heidemann, G., Bae, M. S., Seinfeld, J. H., Flagan, R. C., Cary, R. A., Smith, D., Huebert, B. J., Bertram, T., Howell, S., Kline, J. T., Quinn, P., Bates, T., Turpin, B., Lim, H. J., Yu, J. Z., Yang, H., and Keywood, M. D.: ACE-Asia intercomparison of a thermal-optical method for the determination of particle-phase organic and elemental carbon, Environ. Sci. Technol., 37, 993-1001, 2003.

Schmid, H., Laskus, L., Abraham, H. J., Baltensperger, U., Lavanchy, V., Bizjak, M., Burba, P., Cachier, H., Crow, D., Chow, J., Gnauk, T., Even, A., ten Brink, H. M., Giesen, K.-P., Hitzenberger, R., Hueglin, C., Maenhaut, W., Pio, C., Carvalho, A., Putaud, J.-P., Toom-Sauntry, D., and Puxbaum, H.: Results of 
the "carbon conference" international aerosol carbon round robin test stage I, Atmos. Environ., 35, 2111-2121, 2001.

Sciare, J., Cachier, H., Oikonomou, K., Ausset, P., Sarda-Estève, R., and Mihalopoulos, N.: Characterization of carbonaceous aerosols during the MINOS campaign in Crete, July-August 2001: a multi-analytical approach, Atmos. Chem. Phys., 3, 17431757, doi:10.5194/acp-3-1743-2003, 2003.

Subramanian, R., Khlystov, A. Y., and Robinson, A. L.: Effect of peak inert-mode temperature on elemental carbon measured using thermal-optical analysis, Aerosol Sci. Technol., 40, 763-780, 2006.

ten Brink, H., Maenhaut, W., Hitzenberger, R., Gnauk, T., Spindler, G., Even, A., Chi, X., Bauer, H., Puxbaum, H., Putaud, J.-P., Tursic, J., and Berner, A.: INTERCOMP2000: the comparability of methods in use in Europe for measuring the carbon content of aerosol, Atmos. Environ., 38, 6507-6519, 2004.
Vignati, E., Karl, M., Krol, M., Wilson, J., Stier, P., and Cavalli, F.: Sources of uncertainties in modelling black carbon at the global scale, Atmos. Chem. Phys., 10, 2595-2611, doi:10.5194/acp-102595-2010, 2010.

Yu, J. Z., Xu, J. H., and Yang, H.: Charring characteristics of atmospheric organic particulate matter in thermal analysis, Environ. Sci. Technol., 36, 754-761, 2002.

Zhi, G. R., Chen, Y. J., Sun, J. Y., Chen, L. G., Tian, W. J., Duan, J. C., Zhang, G., Chai, F. H., Sheng, G. Y., and Fu, J. M.: Harmonizing aerosol carbon measurements between two conventional thermal/optical analysis methods, Environ. Sci. Technol., 45, 2902 2908, doi:10.1021/es102803f, 2011. 